\title{
Specialty choices of medical students and house officers in Karachi, Pakistan
}

\author{
M. Aslam, ${ }^{1}$ A. Ali, ${ }^{1}$ T. Taj, ${ }^{2}$ N. Badar, ${ }^{1}$ W. Mirza, ${ }^{3}$ A. Ammar, ${ }^{1}$ S. Muzaffar ${ }^{1}$ and J.R. Kauten ${ }^{4}$
}

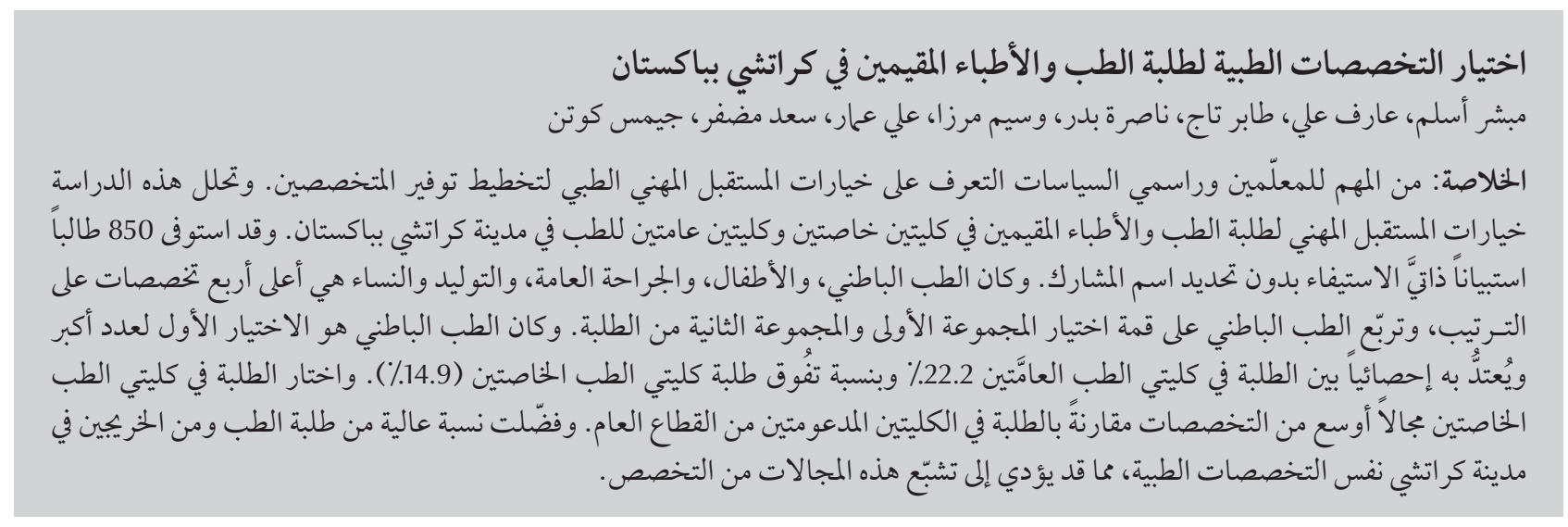

ABSTRACT Understanding patterns of career choices in medicine is important for educators and policy-makers to plan the supply of specialists. This study analysed the career choices made by medical students and house officers in 2 private and 2 public medical schools in Karachi, Pakistan. An anonymous, self-administered questionnaire was completed by 850 students. Internal medicine, paediatrics, general surgery and obstetrics and gynaecology were the 4 highest ranked specialties, with internal medicine ranked top as both the 1st and 2nd choice. Internal medicine was the 1st choice for significantly more students in public than private medical colleges (22.2\% versus $14.9 \%$ ). Students from private medical institutions chose a wider range of specialties than those from publicly-funded colleges. A high proportion of medical students and graduates in Karachi favour the same medical specialties, which may lead to saturation in those areas of specialization.

\section{Choix de spécialisation des étudiants en médecine et des internes à Karachi (Pakistan)}

RÉSUMÉ La compréhension des choix de carrière en médecine est importante pour les éducateurs et les responsables politiques afin de prévoir les effectifs de spécialistes. La présente étude a analysé les choix de carrière réalisés par les étudiants en médecine et les internes dans deux facultés de médecine privées et deux facultés de médecine publiques à Karachi (Pakistan). Un questionnaire anonyme auto-administré a été rempli par 850 étudiants. La médecine interne, la pédiatrie, la chirurgie générale, la gynécologie-obstétrique étaient les quatre spécialisations les plus demandées, la médecine interne étant la spécialisation venant en tête de liste autant comme premier choix que comme deuxième choix. La médecine interne était le premier choix pour un nombre significativement plus élevé d'étudiants des facultés publiques que d'étudiants des facultés privées (22,2 \% contre 14,9\%). Les étudiants des facultés de médecine privées choisissaient des spécialités plus variées que les étudiants des facultés au financement public. Une proportion élevée d'étudiants en médecine et de diplômés à Karachi se prononçaient en faveur des mêmes spécialisations médicales, ce qui peut conduire à une saturation dans ces domaines de spécialisation. 


\section{Introduction}

Medical graduates' choice of specialty can influence the supply of physicians in different areas and can become problematic when there are specialties that are not well represented $[1,2]$. Many researchers have elaborated on this subject and have highlighted the different reasons for the low popularity of some medical specialties, particularly family medicine [3-5], psychiatry [6-8] and radiology [9-11]. Globally, the distribution of physician specialization is a growing concern, as these choices may not meet community needs [12]. Little work has been done to predict the future distribution of medical students among medical specialties [13] and the factors responsible for that distribution $[14,15]$.

It has been observed that choices of particular specialties vary from region to region. Biggs emphasized the importance of annual surveys of medical graduates to quantify future needs and career opportunities [16]. Little research has been done in Pakistan to explore the demographics of specialty choices. A study from a private institution explored the career preferences and choices of final-year students in Pakistan, but the study was limited by a small sample size and was restricted to one institution [17]. Nevertheless, these types of studies can be helpful in career counselling and policy-making [18].

In Pakistan, all medical schools offer a 5-year programme, with basic health sciences as the primary focus during the first 2 years, with gradually increasing exposure to clinical rotations over the next 3 years, followed by a 1-year compulsory internship in a teaching hospital. Potential differences in the career choices of medical students of private versus publicly trained institutions have not been studied previously in Pakistan. Some private medical institutions are following a problem-based learning system [19], whereas all the public medical institutions follow a conventional lecture-based curriculum. In addition, there are certain postgraduate specialty training programmes, such as family medicine, which are only offered in private medical institutions [16]. Kassebaum et al. noted that the medical specialties within an institution can influence the career choices of medical students and that practical experience in a particular field is a major factor spurring a student's interest in a particular specialty [20].

The objective of this research was to determine the career choices of medical students and recent medical graduates in Karachi, Pakistan and to compare the career choices of those trained in private versus public medical colleges.

\section{Methods}

\section{Study design and study setting}

This cross-sectional study was conducted from June 2007 to August 2007 in 2 public and 2 private medical training centres in Karachi, Pakistan. In the public sector, we selected the 2 leading centres out of the 3 medical colleges in Karachi (Dow and Sindh Medical Colleges). Of the 6 private medical colleges in Karachi, we selected the only 2 colleges with fully implemented problembased learning systems (Aga Khan and Ziauddin Medical Colleges).

\section{Study sample}

Only 3rd, 4th and 5th year medical students and house officers were included in the study; 1st and 2nd year students were excluded because of limited exposure to clinical work in the early years of medical studies.

\section{Questionnaire}

The authors developed a self-administered questionnaire in English language, which is the officiallanguage of the medical training centres studied. The 20-item questionnaire collected data on age, sex, self-reported socioeconomic status (low, medium or high), undergraduate courses of study and postgraduate studies plans (inland, abroad or undecided). Respondents were asked to indicate their satisfaction with the medical profession (satisfied or not satisfied) and to state their 1st, 2nd and 3rd choices of medical specialty career.

After seeking verbal consent from the participants, data collectors distributed the questionnaires to the students and house officers and collected them from the different wards of the teaching hospitals of each individual medical institution. The same questionnaire was used for data collection at each of the medical centres.

The questionnaire was pre-tested on 30 participants from each of the medical centres to determine the response and applicability of the tool. Changes were made in the questionnaire accordingly (unpublished data).

The Department of Community Medicine, Sindh Medical College, gave ethical approval for the study. An information sheet was attached with each questionnaire to provide project details, rights of the participants and notification that completing the questionnaire represented informed consent. The questionnaire was anonymous to ensure the confidentiality of the data.

\section{Statistical analysis}

Data were entered and validated in EpiData, version 3.1. Data analysis was performed in SPSS, version 14. A selfreported choice of different medical and non-medical specialties was the defined outcome.

Chi-squared and $t$-tests were applied for categorical and continuous variables respectively to test the statistical significance at a $95 \%$ confidence level. Logistic regression was also applied to determine statistically significant differences after controlling for possible confounders. 


\section{Results}

A total of 909 medical students and house officers participated in the study ( 285 from private colleges and 624 from public colleges). Almost three-quarters of participants were males (71.5\%) (Table 1). Their ages ranged from 19 to 28 years, with a mean age of 22 (SD 1.7 ) years. There was no significant difference in mean age between those attending public or private universities. However, significantly more respondents at private colleges were of high socioeconomic class and of female sex than those at public colleges. Similar proportions of respondents from public and private institutions were satisfied with the medical profession $(82.8 \%$ in private and $79.1 \%$ in public colleges)

Some of the respondents $(n=59)$ did not answerthequestion about career choices and so 850 medical students and house officers were included in the final analysis. The ranking of the top 10 medical specialties was made according to the participants' 1st, 2nd and 3rd career choices. Internal medicine, paediatrics, general surgery, and obstetrics and gynaecology were the 4 highest ranked specialties (Table 2). Internal medicine was the favourite, with $20.5 \%$ of students/graduates reporting it as their 1st choice, followed by surgery (15.0\%), paediatrics (13.5\%), and obstetrics and gynaecology (9.3\%). Internal medicine was also the top-ranked 2 nd choice specialty $(17.2 \%)$, followed by paediatrics (12.8\%), obstetrics and gynaecology (9.3\%), and surgery (9.0\%). For the 3rd choice specialty, internal medicine was also popular (11.2\%) but ranked below paediatrics (15.3\%).

Analysis of the 1st choice career showed that the top choice, internal medicine, was chosen by significantly more students and graduates from public medical colleges $22.2 \%$ than private medical colleges $(14.9 \%)(P=0.01)$ (Table 3). General surgery and paediatrics were the next most highly ranked by similar proportions of students from both sectors. Although a higher proportion of public college students (10.8\%) stated obstetrics and gynaecology as their 1st career choice than did those attending private institutions (5.2\%), the difference was not statistically significant after controlling for the effect of sex and socioeconomic status as confounders. A significantly higher proportion of participants from the private medical centres chose specialization in orthopaedics (5.1\%) as compared to those attending the public medical centres $(0.6 \%)(P=0.02)$ (Table 3). Other specialties mentioned by the students from private medical institutes as 1 st career choice included several other options.

\begin{tabular}{|c|c|c|c|c|c|c|}
\hline Variable & \multicolumn{2}{|c|}{$\begin{array}{l}\text { Private university } \\
\qquad(\boldsymbol{n}=\mathbf{2 8 5})\end{array}$} & \multicolumn{2}{|c|}{$\begin{array}{l}\text { Public university } \\
\qquad(n=624)\end{array}$} & Statistics & $P$-value \\
\hline \multirow[t]{2}{*}{ Mean age $(S D)$ years } & \multicolumn{2}{|c|}{$22.7(1.6)$} & \multicolumn{2}{|c|}{$22.2(1.8)$} & $t=-0.79$ & 0.28 \\
\hline & No. ${ }^{a}$ & $\%$ & No. ${ }^{a}$ & $\%$ & & \\
\hline \multicolumn{7}{|l|}{ Sex } \\
\hline Male & 168 & 59.4 & 482 & 77.7 & \multirow[t]{2}{*}{$\chi^{2}=32$} & \multirow[t]{2}{*}{$<0.001$} \\
\hline Female & 115 & 40.6 & 138 & 22.3 & & \\
\hline \multicolumn{7}{|l|}{ Socioeconomic status } \\
\hline Low & 27 & 9.9 & 96 & 15.7 & \multirow{3}{*}{$\chi^{2}=9.8$} & \multirow{3}{*}{0.007} \\
\hline Middle & 207 & 75.5 & 461 & 75.2 & & \\
\hline High & 40 & 14.6 & 56 & 9.1 & & \\
\hline \multicolumn{7}{|c|}{ Postgraduate studies plan } \\
\hline Inland & 62 & 27.4 & 188 & 47.6 & \multirow{3}{*}{$\chi^{2}=41$} & \multirow{3}{*}{$<0.001$} \\
\hline Abroad & 135 & 59.7 & 122 & 30.9 & & \\
\hline Undecided & 29 & 12.8 & 85 & 21.5 & & \\
\hline \multicolumn{7}{|c|}{ Satisfaction with medical profession } \\
\hline Satisfied & 231 & 82.8 & 484 & 79.1 & \multirow[t]{2}{*}{$\chi^{2}=1.6$} & \multirow[t]{2}{*}{0.11} \\
\hline Not satisfied & 48 & 17.2 & 128 & 20.9 & & \\
\hline \multicolumn{7}{|l|}{ Year in medical school } \\
\hline 3rd year & 84 & 29.5 & 131 & 21.0 & & \\
\hline 4th year & 77 & 27.0 & 206 & 33.0 & & \\
\hline 5 th year & 59 & 20.7 & 156 & 25.0 & & \\
\hline House officer & 65 & 22.8 & 131 & 21.0 & & \\
\hline
\end{tabular}

${ }^{a}$ Data missing in some categories.

$S D=$ standard deviation . 


\begin{tabular}{|c|c|c|c|c|c|c|}
\hline Rank & 1st choice & $\begin{array}{c}\% \\
(n=850)\end{array}$ & 2nd choice & $\begin{array}{c}\% \\
(n=646)\end{array}$ & 3rd choice & $\begin{array}{c}\% \\
(n=412)\end{array}$ \\
\hline 1 & Internal medicine & 20.5 & Internal medicine & 17.2 & Paediatrics & 15.3 \\
\hline 2 & General surgery & 15.0 & Paediatrics & 12.8 & Internal medicine & 11.2 \\
\hline 3 & Paediatrics & 13.5 & $\begin{array}{l}\text { Obstetrics \& } \\
\text { Gynaecology }\end{array}$ & 9.3 & $\begin{array}{l}\text { Obstetrics \& } \\
\text { Gynaecology }\end{array}$ & 10.2 \\
\hline 4 & $\begin{array}{l}\text { Obstetrics \& } \\
\text { Gynaecology }\end{array}$ & 9.3 & General surgery & 9.0 & General surgery & 8.7 \\
\hline 5 & Cardiology & 7.6 & Cardiology & 6.0 & Cardiology & 8.7 \\
\hline 6 & Cardiac surgery & 3.5 & ENT & 4.8 & Dermatology & 7.3 \\
\hline 7 & Dermatology & 3.4 & Ophthalmology & 4.0 & Psychiatry & 4.6 \\
\hline 8 & Psychiatry & 2.5 & Neurology & 4.0 & Neurology & 3.6 \\
\hline 9 & Neurology & 2.5 & Dermatology & 3.9 & Neurosurgery & 3.2 \\
\hline 10 & Ophthalmology & 2.3 & Radiology & 3.9 & Ophthalmology & 2.7 \\
\hline $\mathrm{n} / \mathrm{a}$ & Other & 20.0 & Other & 25.0 & Other & 24.5 \\
\hline
\end{tabular}

$E N T=$ ear, nose, throat; $n / a=$ not applicable.

Those reported by more than 1 student were: neurosurgery $(3.2 \%)$, gastroenterology $(2.5 \%)$, urology $(2.0 \%)$, ear, nose and throat (ENT) (2.0\%), family medicine (1.8\%), radiology (1.4\%), oncology (1.4\%), nephrology (1.0\%), endocrinology $(1.0 \%)$, anaesthesiology (0.7\%) and chest medicine (0.7\%). Among the public medical school respondents, other specialties included: ENT (1.9\%), neurosurgery (1.6\%), anaesthesiology (1.4\%), gastroenterology (1.3\%), radiology (1.1\%), $\mathrm{PhD}$ in basic sciences (1.1\%), plastic surgery (1.1\%), nephrology (1.0\%), chest medicine (0.6\%), Masters in Business Administration $(0.5 \%)$, endocrinology $(0.3 \%)$ and community medicine $(0.3 \%)$, haematology (0.3\%), urology (0.3\%).

\section{Discussion}

Other studies have identified and analysed factors that influence the career choices of medical students and graduates [21] as well as factors responsible for career changes [22]. Khater-Menassa and Major in Lebanon reported that personal interest in the field, intellectual opportunities and social responsibilities were the major factors that influenced medical students' career choices [21].
To be able to begin to understand how career choices are made, it is important to analyse how the medical education system influences students to enter into certain medical specialties. Bethune et al. reported changes in career choices with students' progression through medical school [23]. This process of a student gaining experience as training progresses highlights the influence of curriculum and environment on the career choices of students.

An analysis of the top-10 list of preferred career choices in medicine revealed some interesting information. Internal medicine, paediatrics, general surgery and obstetrics and gynaecology were the 4 highest ranked specialties by our respondents, which is consistent with the findings reported by Huda and Yousuf from a medical university in Pakistan [17]. The health service in Pakistan is characterized by a high level of competition for market share in lucrative fields of medical practice such as cardiology, and different levels of opportunities are present for different specialties. Government health policy has been largely silent about organizing and regulating medical services; however, improvements have been seen.
There were several fields of medicine, including family medicine, endocrinology, nephrology and radiology that were not high priority choices among our medical students, private or public. Community medicine and forensic medicine were not highly rated choices by either group. As a result, serious manpower deficiencies in these fields may exist. Manpower shortages in basic medical science and research faculty already exist in developing countries such as ours [17].

The ability to understand and predict a medical student's choice of specialization is a complex process and is being studied elsewhere $[15,24,25]$. It is considered as a new field of study that warrants further exploration [23]. Armed with information about career preferences, medical education policy in Pakistan can be structured to facilitate the redistribution of medical students and physicians to underserved areas of specialization such as primary care. It has been noted that areas with higher ratios of primary care physicians to population have much lower total health care costs than other areas, possibly as a result of the better preventive care and lower hospitalization rates that accompany good primary care [26]. It is essential to ensure that an adequate number of 


\begin{tabular}{|c|c|c|c|c|c|}
\hline \multirow[t]{2}{*}{ Medical specialty } & \multicolumn{2}{|c|}{$\begin{array}{l}\text { Private university } \\
\qquad(n=269)\end{array}$} & \multicolumn{2}{|c|}{$\begin{array}{l}\text { Public university } \\
\qquad(n=581)\end{array}$} & \multirow[t]{2}{*}{$P$-value ${ }^{a}$} \\
\hline & No. & $\%$ & No. & $\%$ & \\
\hline Internal medicine & 40 & 14.9 & 129 & 22.2 & 0.01 \\
\hline General surgery & 38 & 14.1 & 85 & 14.6 & 0.1 \\
\hline Paediatrics & 31 & 11.5 & 80 & 13.8 & 0.4 \\
\hline Obstetrics \& gynaecology & 14 & 5.2 & 63 & 10.8 & 0.1 \\
\hline Cardiology & 27 & 10.0 & 36 & 6.2 & 0.2 \\
\hline Cardiac surgery & 11 & 4.1 & 18 & 3.1 & 0.6 \\
\hline Dermatology & 7 & 2.6 & 21 & 3.6 & 0.8 \\
\hline Psychiatry & 7 & 2.6 & 14 & 2.4 & 0.8 \\
\hline Neurology & 12 & 4.5 & 9 & 1.5 & 0.08 \\
\hline Ophthalmology & 9 & 3.3 & 10 & 1.7 & 0.15 \\
\hline Orthopaedics & 14 & 5.1 & 4 & 0.6 & 0.02 \\
\hline Other & 59 & 21.9 & 112 & 19.3 & - \\
\hline
\end{tabular}

${ }^{a}$ After controlling for sex and socioeconomic status in logistic regression.

physicians are providing care in all areas of primary care. Family medicine as a speciality is still short of its predicted needs [17] as there are few opportunities for postgraduate training in family medicine in Pakistan.

While a national medical education policy has been developed by the government of Pakistan, there is no specific policy to address the need or mechanisms for determining the number and areas for specialties in medical education. National policy cannot influence the private medical institutions; however, there are other ways of promoting and ensuring the practice of national policy. These can include developing and promoting formal collaboration between public and private institutions, for example with exchange programmes for faculty and students and funding for research.

There are a number of factors explaining the decision-making of publicly trained versus privately trained medical students when it comes to the choice of medical speciality. In our study students and house officers with an education from a private medical institution chose a wider range of specialties than did those trained in public colleges. A higher percentage of students receiving an education from a private medical school are affluent or the children of physicians. These students may have a broader exposure to the full spectrum of medical specialties. In addition, the private medical centres chosen for this study follow a problem-based learning system [19], which has been shown to develop better psychosocial skills in students and a better attitude toward patients than students trained in more traditional ways [27].

One limitation in our study is selection bias of medical training centres and their students. Medical students were chosen from all medical school classes to minimize selection bias. Variations were expected to be minimal as participants were chosen in the same manner irrespective of whether they were the products of private or public medical training.

Further research is needed to study the factors that influence a medical trainee to choose a particular field of study. Better knowledge of the demographics and need for medical specialties across Pakistan and other countries in the region is needed to determine educational direction and policy. This capability will better prepare developing countries to meet their present and future medical needs.

\section{Conclusions}

This study has shown that a high proportion of medical students and recent medical graduates in Karachi, Pakistan choose the same medical specialties. This may lead to saturation in those areas of specialization and as a result leave the population underserved in other important areas. Students with an education from a private medical institution chose a wider range of specialties than did those trained in publicly-funded colleges.

\section{Acknowledgements}

The authors gratefully acknowledge the contribution of Waqas Javed Siddiqui (Jinah Postgraduate Medical Centre), Zeenat Zehra, Zehra Hassan (Dow Medical College), Ali Abbas (medical student, Ziauddin Medical University) and Tauseef and Bilal Abid (medical student, Aga Khan University), for facilitating the questionnaire administration at the different medical universities. 


\section{References}

1. Cooper RA et al. Economic and demographic trends signal an impending physician shortage. Health Affairs (Project Hope), 2002, 21:140-154.

2. Fisher ES et al. The implications of regional variations in Medicare spending. Part 2: health outcomes and satisfaction with care. Annals of Internal Medicine, 2003, 138:288-298.

3. Campos-Outcalt D et al. Family medicine specialty selection: a proposed research agenda. Family Medicine, 2007, 39:585-589.

4. Starfield B. Primary care in Canada: coming or going? Healthcare Papers, 2008, 8:58-62, discussion 64-67.

5. McGaha AL et al. Responses to medical students' frequently asked questions about family medicine. American Family Physician, 2007, 76:99-106.

6. Lehane M. Psychiatry: the career of choice. Nursing Standard, 2005, 20:34-35.

7. Goldacre MJ et al. Career choices for psychiatry: national surveys of graduates of 1974-2000 from UK medical schools. British Journal of Psychiatry, 2005, 186:158-164.

8. Wigney T, Parker G. Medical student observations on a career in psychiatry. Australian and New Zealand Journal of Psychiatry, 2007, 41:726-731.

9. Maj L, Baerlocher MO: Factors leading to radiology career selection: results of the 2004 National Physician Survey. $\mathrm{Ca}$ nadian Association of Radiologists Journal, 2006, 57(3):175-178.

10. Kazerooni EA et al. Medical students' attitudes toward radiology: comparison of matriculating and graduating students. Academic Radiology, 1997, 4:601-607.

11. Ehara S. Preclinical medical student education in radiology. American Journal of Roentgenology, 2007, 189(3):W166.

12. Brotherton SE, Rockey PH, Etzel SI. US graduate medical education, 2003-2004. Journal of the American Medical Association, 2004, 292:1032-1037.

13. Saigal $\mathrm{P}$ et al. Factors considered by medical students when formulating their specialty preferences in Japan: findings from a qualitative study. BMCMedical Education, 2007, 7:31.

14. Lawrence J, Poole P, Diener S. Critical factors in career decision making for women medical graduates. Medical Education, 2003, 37:319-327.

15. Kassebaum DG, Szenas PL, Schuchert MK. Determinants of the generalist career intentions of 1995 graduating medical students. Academic Medicine, 1996, 71:198-209.
16. Avgerinos ED et al. Greek medical students' career choices indicate strong tendency towards specialization and training abroad. Health Policy (Amsterdam), 2006, 79:101-106.

17. Khan $\mathrm{H}$ et al. Problem-based versus conventional curricula: influence on knowledge and attitudes of medical students towards health research. PLoS ONE, 2007, 2:632.

18. Biggs JS. Postgraduate medical training in Pakistan: observations and recommendations. Journal of the College of Physicians and Surgeons of Pakistan, 2008, 18:58-63.

19. Huda N, Yousuf S. Career preference of final year medical students of Ziauddin Medical University. Education for Health (Abingdon, England), 2006, 19:345-353.

20. Petrides KV, McManus IC. Mapping medical careers: questionnaire assessment of career preferences in medical school applicants and final-year students. BMC Medical Education 2004, 4:18.

21. Nandi PL et al. Undergraduate medical education: comparison of problem-based learning and conventional teaching. Hong Kong Medical Journal, 2000, 6:301-306.

22. Mutha S, Takayama JI, O'Neil EH. Insights into medical students' career choices based on third- and fourth-year students' focus-group discussions. Academic Medicine, 1997, 72:635-640.

23. Sobral DT. Selective training and cross-year clinical tutoring as educational influences on generalist career choice. Education for Health (Abingdon, England), 2001, 14(2):295-303.

24. Bethune $\mathrm{C}$ et al. Family medicine as a career option: how students' attitudes changed during medical school. Canadian Family Physician, 2007, 53(5):881-885.

25. Khater-Menassa B, Major S. Factors influencing the choice of specialty among medical students in Lebanon. Le JournalMedical Libanais, 2005, 53:16-20.

26. Scott I et al. Why medical students switch careers: changing course during the preclinical years of medical school. Canadian Family Physician, 2007, 53:95, 95, 1-5, 94.

27. Caminal $\mathrm{J}$ et al. The role of primary care in preventing ambulatory care sensitive conditions. European Journal of Public Health, 2004, 14:246-251. 